\title{
Effects of $Y$-type spillway lateral contraction ratios on debris-flow patterns and scour features downriver of a check dam
}

\author{
Huayong Chen ${ }^{1,2}$, Jinfeng Liu ${ }^{1,2}$, and Wanyu Zhao ${ }^{1,2}$ \\ ${ }^{1}$ Key Laboratory of Mountain Hazards and Earth Surface Process Chinese Academy of Sciences (CAS), \\ Chengdu, 610041, China \\ ${ }^{2}$ Institute of Mountain Hazards and Environment, CAS, Chengdu, 610041, China \\ Correspondence to: Huayong Chen (hychen@imde.ac.cn)
}

Received: 25 May 2016 - Published in Nat. Hazards Earth Syst. Sci. Discuss.: 27 June 2016

Revised: 20 October 2016 - Accepted: 24 October 2016 - Published: 28 November 2016

\begin{abstract}
Debris flows often cause devastating damage to property and can injure or kill residents in mountainous areas. The construction of check dams in debris-flow valleys is considered a useful strategy for mitigating the damages downstream. In this paper, a new type of spillway structure with lateral contraction was proposed to distribute debris flows after the check dam storage filled up. Four different lateral contraction ratios of the spillway were considered in experiments that investigated debris-flow patterns, scour characteristics, and energy dissipation rates when debris flows passed through the spillway. The results indicated that lateral contraction considerably influenced the extension of debris-flow nappes. The drop length of the nappe at $\eta=0.7$ ( $\eta$ means lateral contraction ratio) was approximately 1.4 times larger than at $\eta=0.4$. The collision, friction, and mixing forces between the debris-flow nappes and debris flows in downstream plunge pools dissipated much of the debris-flow kinetic energy, ranging from 42.03 to $78.08 \%$ at different contraction ratios. Additionally, based on a dimensionless analysis, an empirical model was proposed to predict the maximum scour depth downriver of a check dam. It indicated that the results calculated by the model exhibited good agreement with the experimental results.
\end{abstract}

\section{Introduction}

Debris flows are formed by poorly sorted, water-saturated materials that mobilize in upstream regions of valleys and surge down slopes in response to gravitational attraction (Iverson, 1997). Large-scale debris flows were triggered by intensive rainfalls after the 5.12 Wenchuan earthquake, including the Zhouqu debris flow, the Wenjia gully debris flow, and the Hongchun gully debris flow (Wang, 2013; Yu et al., 2013; Tang et al., 2015). On 8 August 2010, a large debris flow occurred in the Luojiayu gully, northern Zhouqu County, Gansu Province. The flow destroyed six villages, blocked the Bailongjiang River, resulting in the formation of a lake that inundated over half of Zhouqu County, and displaced or killed 1765 people (Cui et al., 2013). Usually, large-scale debris flow events involve substantial erosion upstream (Ni et al., 2012; Yu et al., 2013), and large volumes of solid materials are transported from the initiation zone to downstream areas.

The construction of check dams is considered one of the most effective ways to store solid materials and control soil erosion in a valley. This structural countermeasure is commonly used to stabilize bank slopes, flatten the gradients of valleys, reduce flow velocity, and decrease the peakdischarge of debris flows (Lenzi, 2002; Mizuyama, 2008; Remaître et al., 2008; Remaître and Malet, 2010). Two main types of check dams are applied to control debris flows (i.e., closed-type and opened-type). Opened-type dams trap boulders, cobble, and gravel, allowing small particles, fine sediments, and water to pass through the dams (Abedini et al., 2012). Closed-type damns not only trap the coarse particles but also retain most small particle materials (Heumader, 2000; Lien, 2003). Generally, the dam storage volume of a closed-type check dam is quickly filled with debris-flow material when a large debris flow occurs. The sequent debris flows directly overflow the check dam, which can lead to se- 
rious scour on and around the foundation of the check dam (Fig. 1).

Flow patterns and scour caused by the discharge of clear water or sediment flows has been well studied in hydraulic engineering. The characteristics of free-falling nappes behind the spillway of a gravity dam were investigated and the drop length of the free jet was predicted based on the energy equation in which the energy dissipation was neglected at two chosen cross sections (Toombes et al., 2008). Experimental investigations of aeration associated with overflow dams with curved surfaces were carried out, and empirical correlations predicting the aeration efficiencies of these differently shaped spillways were developed (Chu et al., 2014). An interpolation formula for predicting scour depth was proposed based on experimental data. It indicated that the maximum scour increased with increasing discharge and decreased with increasing downstream tail water depth (Adduce et al., 2005). In addition to the discharge and downstream tail water depth, the characteristic grain size and the plunge angle were also considered for scour depth prediction (Bormann and Julien, 1991). Considerable attention has been given to the flow patterns and scour caused by clear flows or sediment flows behind dams. However, few studies have investigated the debris-flow patterns and scour features behind check dams (Pan et al., 2013), especially for spillway structures with lateral contraction. The flow patterns and scour features caused by debris flows are different from those caused by clear water or sediment flows due to different flow densities, cohesion, and particle volume concentrations. The investigation on characteristics of debris flows discharging and scouring with the new spillway ( $Y$-type spillway) can enrich our knowledge of scour control for debris-flow mitigation.

In this paper, a new spillway structure with lateral contraction is proposed. Experiments with different spillway contraction ratios were conducted to study the characteristics of debris-flow nappes and scour after debris flows overflowed the check dam. For each experimental test, video cameras were used to record the trajectories of debris-flow nappes. The energy dissipation rate was analyzed due to the varying lateral contraction ratios. Finally, an empirical model based on dimensionless analysis was proposed to predict the maximum scour depth downriver of a check dam.

\section{Experimental setup}

The experiments were performed at the Dongchuan Debris Flow Observation and Research Station (DDFORS) in Dongchuan District, Yunnan Province, China. Generally, the experimental flume consisted of a hopper, a gate, a rectangular channel, and the downstream erodible bed (Fig. 2a). The rectangular channel was approximately $4.0 \mathrm{~m}$ long, $0.4 \mathrm{~m}$ wide, and $0.4 \mathrm{~m}$ high, with a slope of $8^{\circ}$ (Fig. 2b). A check dam made of steel material was located at the end of the rect-

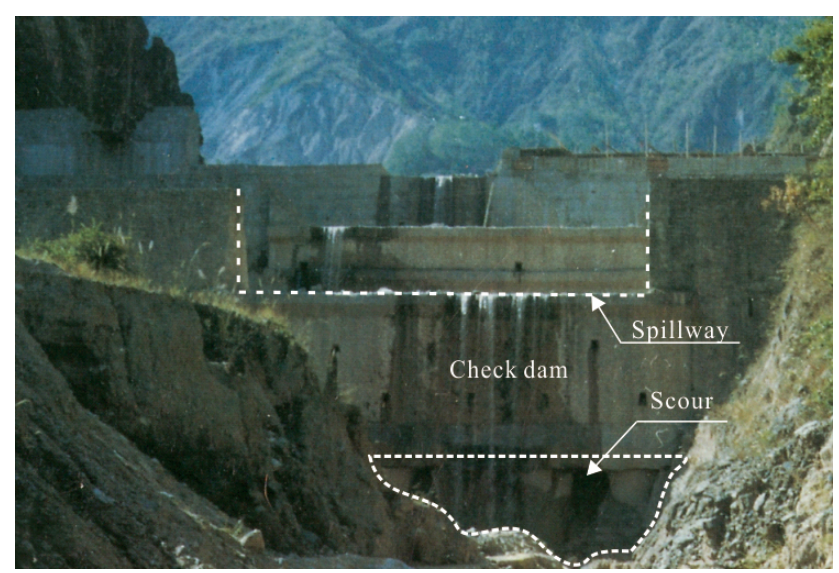

Figure 1. An example of foundation scour downriver of a check dam.

angular channel. The shape of the spillway inlet was a $0.20 \mathrm{~m}$ wide by $0.10 \mathrm{~m}$ high rectangle. The outlet was shaped like a capital letter " $Y$ ". The top width of the outlet was equal to that of the inlet. The bottom width ranged from 0.06 to $0.12 \mathrm{~m}$ due to the different contraction ratios of the spillway. The dimensions of the spillway are shown in Fig. 2c.

The lateral contraction ratio $\eta$ is defined as follows:

$\eta=\frac{B-b}{B}$,

where $B$ is the width of the spillway inlet and $b$ is the width of the spillway outlet. When $b=B, \eta=0$.

The storage of the check dam was filled with the solid materials from Jiangjia ravine, with a slope of $3^{\circ}$. The diameter of the solid material was smaller than $20.0 \mathrm{~mm}$. Its particle size distribution is shown in Fig. 3. Particle size distribution may affect the debris-flow density and flow motion along the channel. The solid materials used in this experiment were prepared according to the sample of typical debris flows and excluded particles larger than $20.0 \mathrm{~mm}$ due to the limitations of the experimental conditions. The diameter of the solid materials in the erodible bed was also smaller than $20.0 \mathrm{~mm}$. In addition, the clay and fine particles (smaller than $1.0 \mathrm{~mm}$ ) were excluded to avoid the effects of matric suction on the development of the scour hole. The particle size distribution of the erodible bed materials is also shown in Fig. 3.

In each experimental test, a laser range finder (LRF) was set at the end of the erodible bed to monitor the depth of the debris flow during the entire process, as shown in Fig. 4. The LRF measured the distance between the original bottom and the laser receiver. When debris flows flowed over the channel bottom, the LRF measured the distance between the debris-flow surface and the laser receiver. The distance difference was the flow depth. The measurement range of the LRF was up to $30.0 \mathrm{~m}$, with an accuracy of $\pm 0.001 \mathrm{~m}$. The sampling frequency of the LRF was about $31.0 \mathrm{~Hz}$. The elevation difference between the initial position and the flow 

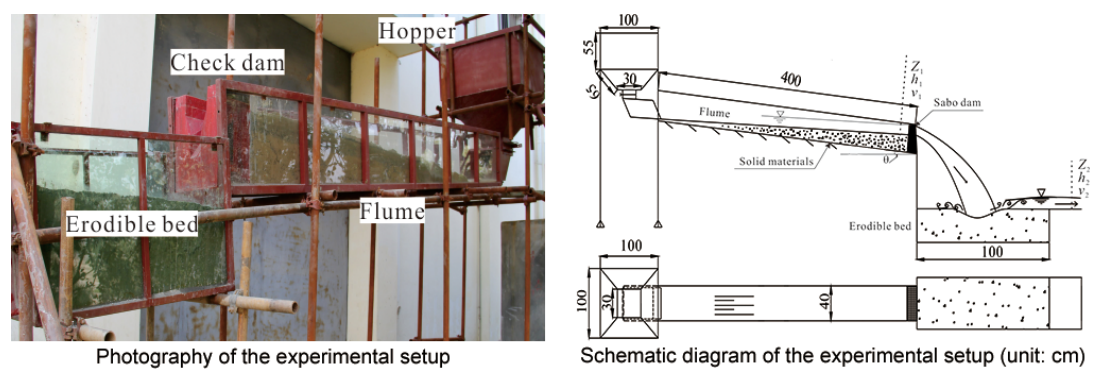

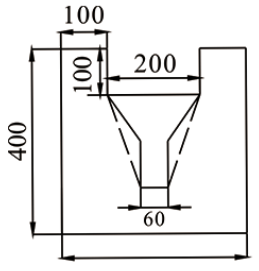

400

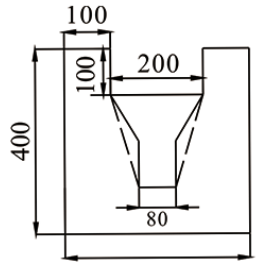

400

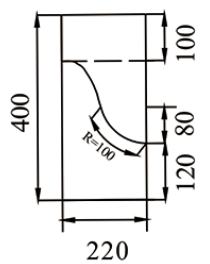

(a)

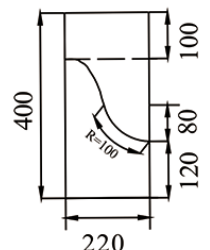

(b)

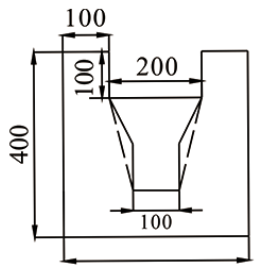

400

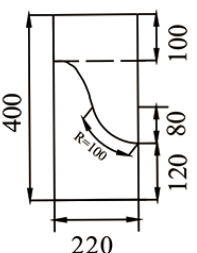

(c)

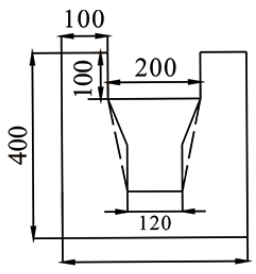

400

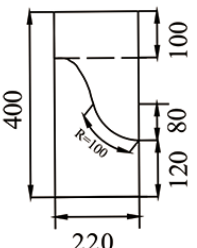

(d)

Figure 2. Experimental setup.

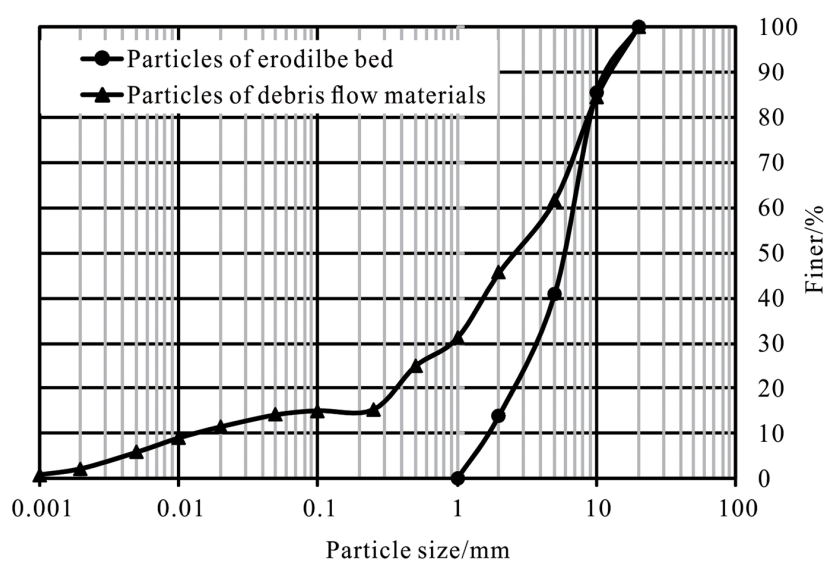

Figure 3. The particle size distribution of samples for the debris flows and erodible bed.

surface was the measured flow depth. The Froude number in our experiment ranged from 1.14 to 1.16 . It meant that the debris flows in the experiments were supercritical flow. An example of the measured results is shown in Fig. 5. It reveals that although the debris-flow process is not steady over time, the debris flow over a short period can be considered steady flow. Therefore, the energy conservation equation derived based on the steady flow assumption can be applied to analyze the energy dissipation rate of a debris flow.

\section{Experimental results and analysis}

\subsection{Flow patterns of different contraction ratios}

When debris flows overflowed the spillway with a high lateral contraction ratio $(\eta=0.7)$, the flow depth and velocity increased dramatically. The debris-flow nappe clearly extended in the flow direction. Furthermore, the debris flows near both side walls, which were forced to change direction by the walls, collided at the outlet when the debris flows overflowed from the spillway (Fig. 6a). Decreasing the lateral contraction ratio caused the flow depth and velocity to decrease at the same flow discharge. Therefore, the drop length of the debris-flow nappe decreased in the flow direction. The drop length at $\eta=0.7$ was approximately 1.4 times than at $\eta=0.4$ (Table 1). Lateral contraction not only affected the drop length but also broadened the nappe width due to the collision of debris flows at the outlet (Fig. 6b-d). When $\eta=0.5$, the broadening ratio $\kappa(\kappa$ is the ratio of nappe width to the outlet width) reached its maximum value $(\kappa=2.93$ in Table 1). The nappe width was equal to that of the spillway $(\kappa=1.0)$ when there was no lateral contraction at the spillway.

If debris flows flowing out of the spillway are considered free-motion point masses under the influence of gravity, the trajectory of a debris-flow nappe can be expressed as follows 
Table 1. The main parameters of the debris flow nappe for different contraction ratios.

\begin{tabular}{lrrrr}
\hline Items & (a) & (b) & (c) & (d) \\
\hline Width of the outlet $b / \mathrm{mm}$ & 60.0 & 80.0 & 100.0 & 120.0 \\
Lateral contraction ratio $\eta$ & 0.7 & 0.6 & 0.5 & 0.4 \\
Width of the nappe $W_{\text {Nappe }} / \mathrm{mm}$ & 137.2 & 231.6 & 292.6 & 320.6 \\
Broadening ratio $\kappa\left(\kappa=W_{\text {Nappe }} / b\right)$ & 2.29 & 2.90 & 2.93 & 2.67 \\
Length of the nappe away from the outlet $x_{\mathrm{a}} / \mathrm{m}$ & 0.43 & 0.34 & 0.33 & 0.31 \\
Length of the nappe close to the outlet $x_{\mathrm{c}} / \mathrm{m}$ & 0.25 & 0.21 & 0.21 & 0.18 \\
\hline
\end{tabular}

Notes: $B$ is constant for each spillway type $(B=200.0 \mathrm{~mm})$.

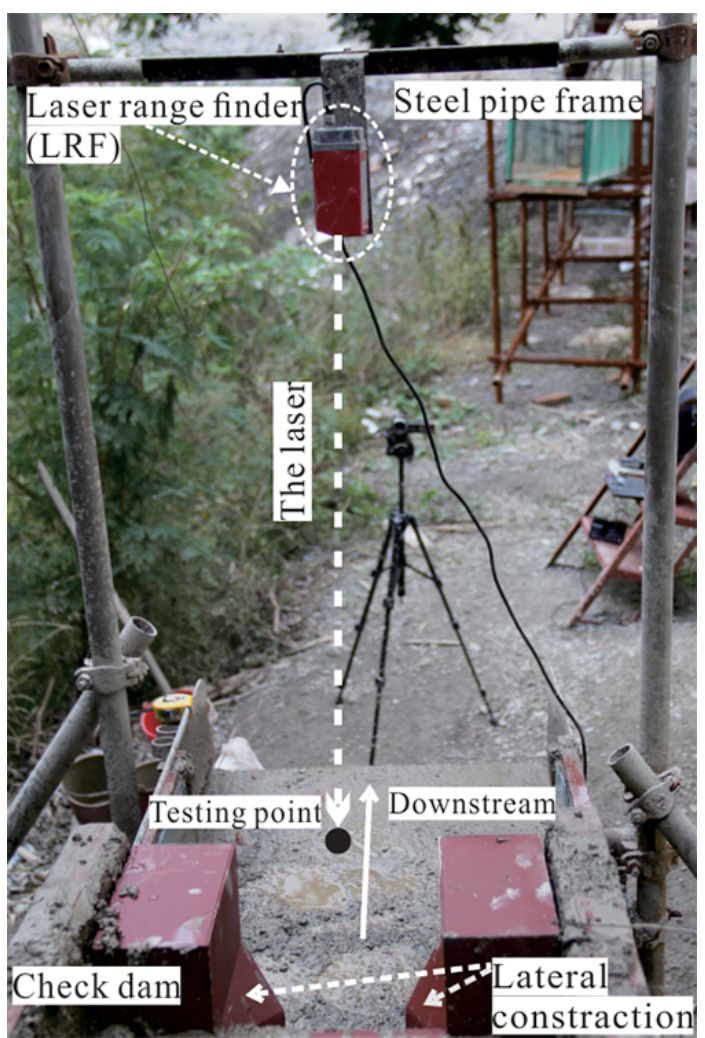

Figure 4. Photograph of the LRF system (the photograph was taken in the downstream direction).

(Fig. 7):

$y=x \operatorname{tg} \varphi+\frac{g}{2 v_{1}^{2} \cos \varphi^{2}} x^{2}$

$x=\frac{v^{2}}{g} \cos \varphi\left(\sqrt{\sin ^{2} \varphi+\frac{2 g y}{v^{2}}}-\sin \varphi\right) \varphi \geq 0$.

When $\varphi=0$, Eq. (2) simplifies to Eq. (3):

$x=\sqrt{\frac{2 v^{2} y}{g}}$,

where $v$ is the initial velocity of the debris flow flowing out of the spillway, $\varphi$ represents the angle of the initial veloc-

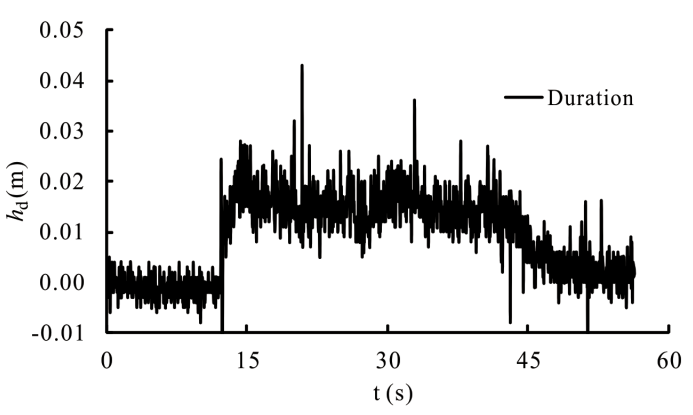

Figure 5. An example of a debris-flow hydrograph.

ity in the horizontal direction, and $y$ is the water elevation difference.

Equation (3) indicates that the nappe extension in the horizontal direction $x$ is proportional to the initial velocity $v$ and square root of the water elevation difference $y$. From Fig. 6 and Table 1, we found that when $\eta=0.7$, the nappe extension was longest in the flow direction. From this point of view, a high lateral contraction ratio increased the distance between the plunge point and the dam toe, which effectively protected the dam foundation from scouring. The hydraulic characteristics of the nappe away from the spillway at different lateral contraction ratios were shown in Figs. 8 and 9. Figure 8 indicates that increasing the lateral contraction ratio decreased the width of the debris-flow nappe. Furthermore, the higher lateral contraction of the spillway strengthened the collision between flows at the spillway outlet. Air bubbles were entrained in the debris flows when the continuum of the debris flows was broken. Figure 9 shows the extent of the debris-flow nappes. The distribution of the flow velocity in the vertical direction at the outlet increased with increasing flow depth due to the effects of boundary friction. Therefore, the longest flow nappes were formed by the debris flows with relatively large velocities at the flow surface.

\subsection{Debris-flow scour features downriver of a check dam}

The scour features of debris flows downriver of a check dam represent one of the most important indexes, which de- 

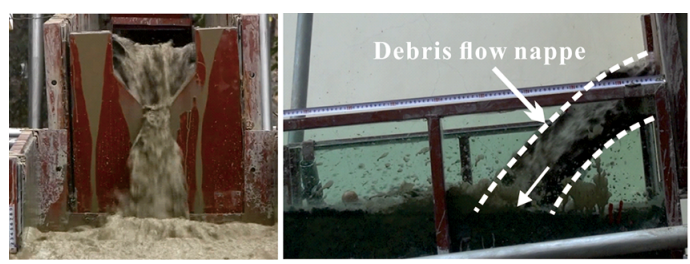

(a) $\eta=0.7$

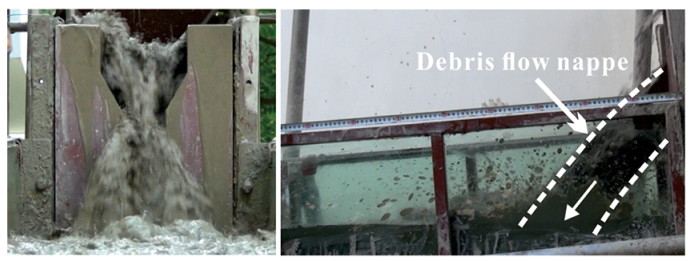

(c) $\eta=0.5$

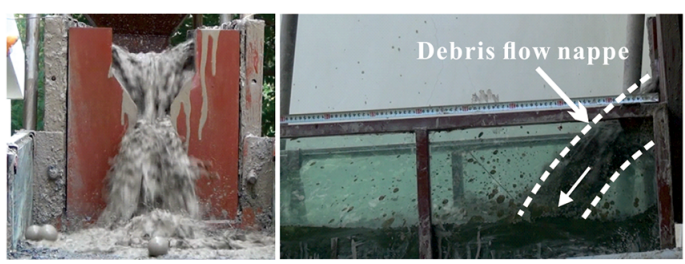

(b) $\eta=0.6$

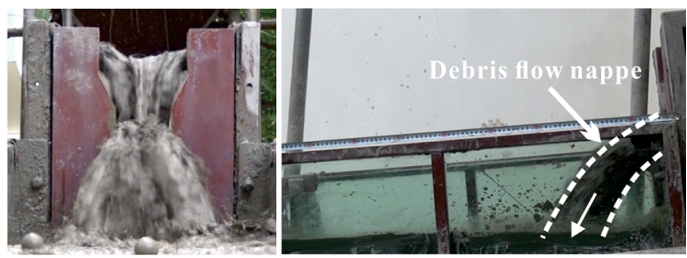

(d) $\eta=0.4$

Figure 6. Various debris flow patterns at different lateral contraction ratios (the pictures on the left were taken from a downstream view).

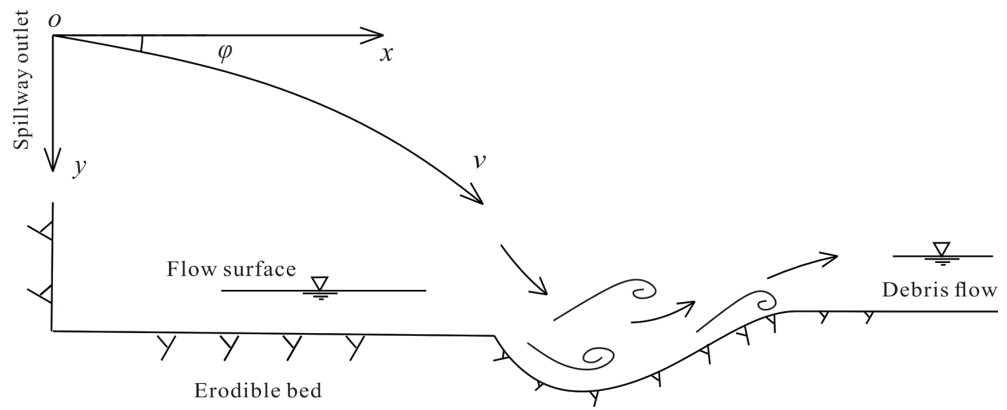

Figure 7. A diagram of dynamic parameters of debris flows.

termines the scour depth at the dam foundation. Figure 10 shows the effects of lateral contraction on the formation of scour holes in an erodible bed. For the same curvature of the spillway surface, decreasing the contraction ratio decreased the maximum scour depth and caused the location of the maximum scour point to shift toward the dam toe due to the decreased debris-flow velocity. The maximum scour depth and its location farther from the dam toe for $\eta=0.7$ were approximately 1.3 and 1.4 times, respectively, larger than for $\eta=0.4$. Although a high lateral contraction ratio extended the debris-flow nappe, it also increased the scour depth in the erodible bed to some extent. In addition, debris-flow density has some effect on the scour depth. Figure 11 indicates the scour depth caused by debris flow with a density of $1200 \mathrm{~kg} \mathrm{~m}^{-3}$ is a bit larger than that caused by debris flow with a density of $1500 \mathrm{~kg} \mathrm{~m}^{-3}$ at a certain lateral contraction ratio (Fig. 11). It was explained that the debris flow with lower particle concentration (lower debris-flow density) initialized and carried more bed materials than that with higher particle concentration (higher debris-flow density) when the other factors were fixed (such as longitudinal slope of gully, debris-flow scale, lateral contraction ratio of the spillway).

\subsection{Energy dissipation at different contraction ratios}

Generally, different energy dissipaters such as the plunge pool (Pagliara et al., 2010; Duarte et al., 2015) or step-pool systems (Yu et al., 2007; Wang et al., 2009, 2012) are required to dissipate the kinetic energy of the surplus flow and prevent the dam foundation and riverbed from scouring when sudden changes to the channel slope occur. The energy dissipation process of the check dam was estimated using the Bernoulli Eq. (4). The rationale behind using this equation was previously mentioned.

The Bernoulli equation between two reference cross sections is written as follows:

$Z_{1}+h_{1}+\alpha_{1} \frac{v_{1}^{2}}{2 g}=Z_{2}+h_{2}+\alpha_{2} \frac{v_{2}^{2}}{2 g}+h_{\mathrm{w}}$.

If $\Delta Z=Z_{1}-Z_{2}$, then Eq. (4) can be transformed into Eq. (5):

$\Delta Z+h_{1}+\alpha_{1} \frac{v_{1}^{2}}{2 g}=h_{2}+\alpha_{2} \frac{v_{2}^{2}}{2 g}+h_{\mathrm{w}}$. 


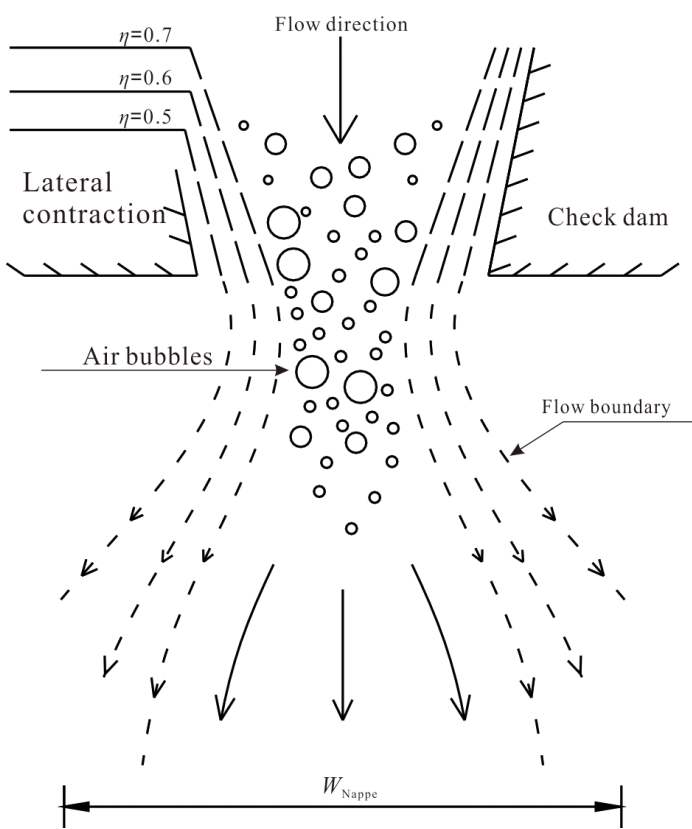

Figure 8. The transverse expansion of a debris flow nappe at different lateral contraction ratios.

Table 2. The energy dissipation rates at different contraction ratios.

\begin{tabular}{lcccc}
\hline \multirow{2}{*}{ Scales } & \multicolumn{4}{c}{ Density $\left(\rho=1.50 \mathrm{~g} \mathrm{~cm}^{-3}\right)$} \\
\cline { 2 - 5 } & $\eta=0.7$ & $\eta=0.6$ & $\eta=0.5$ & $\eta=0.4$ \\
\hline$V=0.16 \mathrm{~m}^{3}$ & $66.43 \%$ & $57.48 \%$ & $52.34 \%$ & $42.03 \%$ \\
$V=0.10 \mathrm{~m}^{3}$ & $75.37 \%$ & $72.94 \%$ & $60.58 \%$ & $67.97 \%$ \\
$V=0.06 \mathrm{~m}^{3}$ & $78.08 \%$ & $73.70 \%$ & $63.61 \%$ & $71.75 \%$ \\
\hline Mean value & $73.29 \%$ & $68.04 \%$ & $58.84 \%$ & $60.58 \%$ \\
\hline
\end{tabular}

The energy dissipation coefficient $\zeta$ can be expressed as follows:

$$
\zeta=1-\frac{h_{2}+\frac{v_{2}^{2}}{2 g}}{\Delta z+h_{1}+\frac{v_{1}^{2}}{2 g}},
$$

where $Z_{1}$ and $Z_{2}$ are the elevations of reference cross sections \#1 and \#2 (Fig. 2b), $h_{1}$ and $h_{2}$ are the depths of debris flows at reference cross sections \#1 and \#2, $v_{1}$ and $v_{2}$ are the velocities of the debris flows at references cross sections \#1 and $\# 2, \alpha_{1}$ and $\alpha_{2}$ are the kinetic energy correction coefficients $\left(\alpha_{1}=\alpha_{2}=1\right)$ (Adamkowski et al., 2006), $\Delta Z$ is the elevation difference between the two reference cross sections, and $h_{\mathrm{w}}$ is the water head loss.

Table 2 indicates that the collision and friction forces between the debris-flow nappes and debris flows in the plunge pool dissipated the kinetic energy of the flows, ranging from 42.03 to $78.08 \%$ at different contraction ratios. In the case of $V=0.16 \mathrm{~m}^{3}$, the energy dissipation rate decreased gradually when the contraction ratio changed from 0.7 to 0.4 because the high contraction ratio increased the number of debrisflow collisions when it passed through the spillway. In the cases of $V=0.10 \mathrm{~m}^{3}$ and $V=0.06 \mathrm{~m}^{3}$, the energy dissipation rate also decreased with decreasing contraction ratios except at $\eta=0.4$. The mean value of the energy dissipation rate demonstrated a good positive correlation with the lateral contraction ratio. In addition, for the same contraction ratio, the energy dissipation rate increased gradually with decreasing debris-flow scale.

\subsection{The empirical equation for estimating the maximum scour depth}

Many empirical equations have been proposed to predict the maximum scour depth over the last several decades (Bormann and Julien, 1991; Adduce et al., 2005; Pan et al., 2013). The main parameters include the unit discharge, characteristic particle size of the erodible bed, water elevation difference and clear water and debris-flow densities. However, most of the empirical equations neglect dimensional homogeneity (the empirical equations should be dimensionally homogeneous). For new type of spillway, the lateral contraction ratio is an important parameter for predicting the maximum scour depth. For a debris flow, the maximum scour depth is mainly determined by the following parameters:

$h_{\mathrm{d}}=f\left(q, g, \rho_{\mathrm{d}}, \rho_{\mathrm{w}}, d_{90}, \eta \ldots\right)$

where $h_{\mathrm{d}}$ is the maximum scour depth, $q$ is the unit discharge of the debris flow, $g$ is the acceleration due to gravity, $\rho_{\mathrm{d}}$ and $\rho_{\mathrm{w}}$ are the debris-flow density and clear water density, respectively (two debris-flow densities were considered, including, $\rho_{\mathrm{d}}=1200 \mathrm{~kg} \mathrm{~m}^{-3}$ and $\rho_{\mathrm{d}}=1500 \mathrm{~kg} \mathrm{~m}^{-3}$ ), $d_{90}$ is the characteristic particle size for erodible bed materials, and $\eta$ is the lateral contraction ratio.

Based on a dimensional analysis, the dimensionless parameters with clear physical meanings are developed as follows:

$\frac{h_{\mathrm{s}}}{d_{90}}=k\left(\frac{q}{d_{90} \sqrt{g d_{90}}}\right)^{a 1}\left(\frac{\rho_{\mathrm{d}}}{\rho_{\mathrm{w}}}\right)^{a 2}(\eta)^{a 3}$,

where $h_{\mathrm{s}} / d_{90}$ is dimensionless scour depth, $k$ is a coefficient, ai is an index $(i=1,2,3), \frac{q}{d_{90} \sqrt{g d_{90}}}$ is the dimensionless discharge, and $\rho_{\mathrm{d}} / \rho_{\mathrm{w}}$ is the dimensionless density.

According to the experimental data, the regression equation can be expressed as follows:

$\frac{h_{\mathrm{s}}}{d_{90}}=3.15\left(\frac{q}{d_{90} \sqrt{g d_{90}}}\right)^{0.51}\left(\frac{\rho_{\mathrm{d}}}{\rho_{\mathrm{w}}}\right)^{-0.1363}(\eta)^{0.7583}$.

The regression equation suggests that the flow density had relatively small effects on the depth of the scour hole. However, the debris-flow discharge and the lateral contraction had strong effects on the maximum depth of the scour hole, which directly determined the kinetic energy of the flow in 


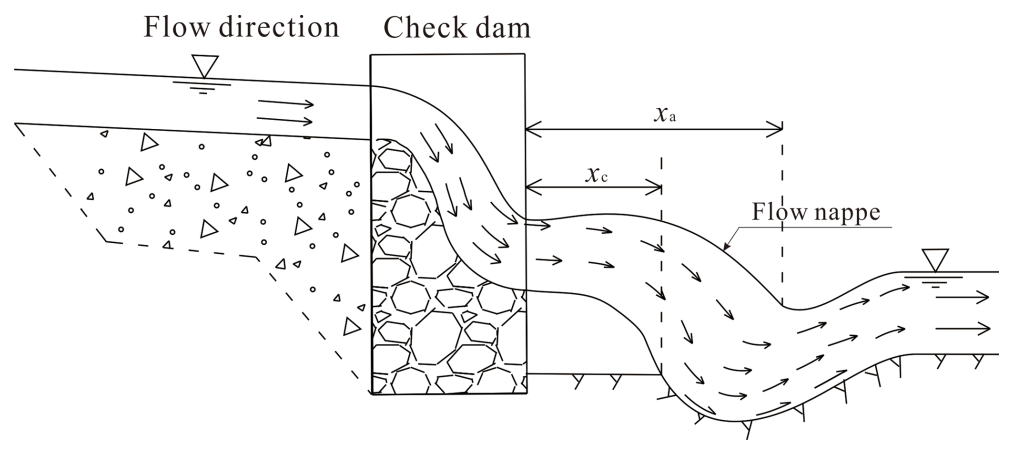

Figure 9. The trajectory of a debris flow nappe.
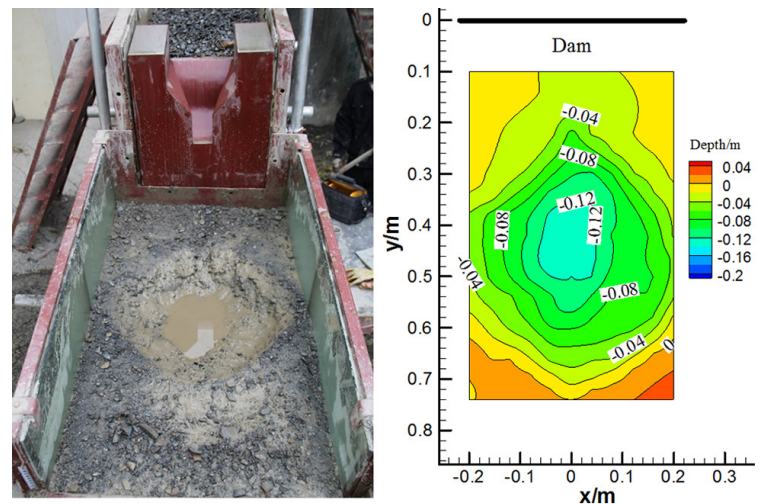

(a) $\eta=0.7, V=0.16 \mathrm{~m}^{3}, \rho=1.50 \mathrm{~g} \mathrm{~cm}^{-3}, b=0.06 \mathrm{~m}$
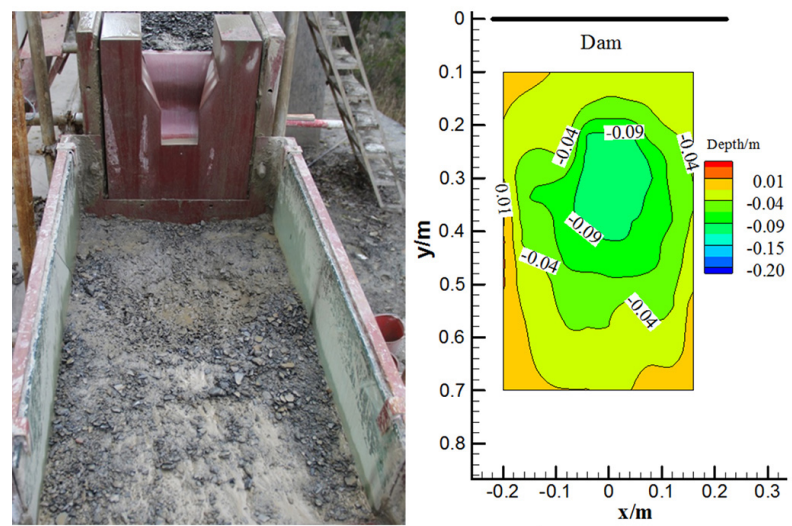

(c) $\eta=0.5, V=0.16 \mathrm{~m}^{3}, \rho=1.50 \mathrm{~g} \mathrm{~cm}^{-3}, \quad b=0.10 \mathrm{~m}$
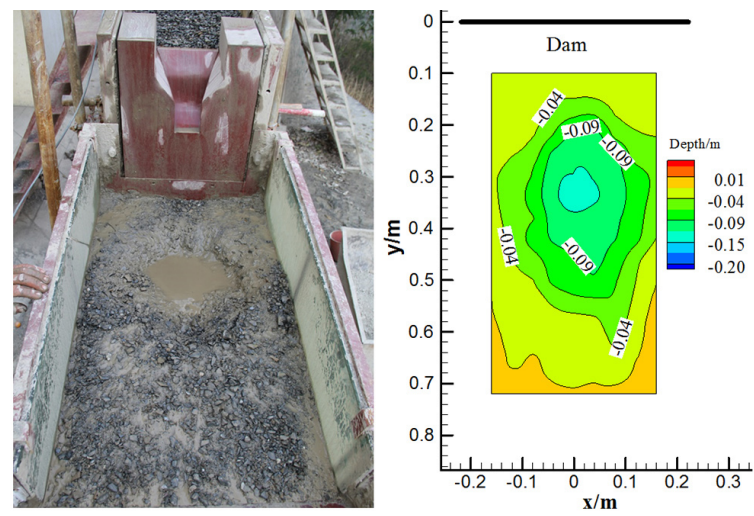

(b) $\eta=0.6, V=0.16 \mathrm{~m}^{3}, \rho=1.50 \mathrm{~g} \mathrm{~cm}^{-3}, b=0.08 \mathrm{~m}$
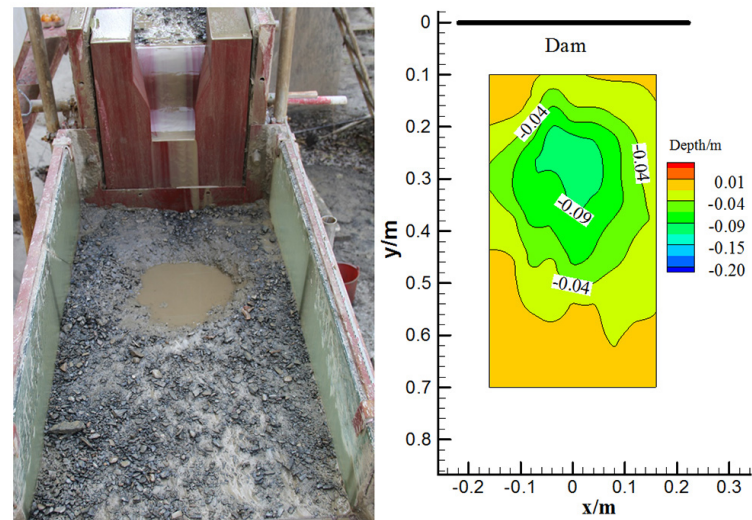

(d) $\eta=0.4, V=0.16 \mathrm{~m}^{3}, \rho=1.50 \mathrm{~g} \mathrm{~cm}^{-3}, b=0.12 \mathrm{~m}$

Figure 10. The shapes of the scour hole downriver of a check dam $\left(V=0.16 \mathrm{~m}^{3}, \rho=1.50 \mathrm{~g} \mathrm{~cm}^{-3}\right)$.

the downstream erodible bed. The validation tests were also performed using the physical experimental model shown in Fig. 2, but under different conditions. Additional experimental data provided in the literature (Ben Meftah and Mossa, 2006) were used to verify the reliability of the regression equation. The predicted results exhibited good agreement with the experimental results. The absolute error was smaller than $15.0 \%$ in most cases (8.33\%), as shown in Fig. 12.

\section{Conclusions and discussions}

\subsection{Conclusions}

The characteristics of debris flows overflowing the new type of spillway were analyzed at different lateral contraction ratios. The energy dissipation rate and an empirical model for predicting the maximum scour depth were also studied in this paper. The following conclusions were drawn from this analysis. 

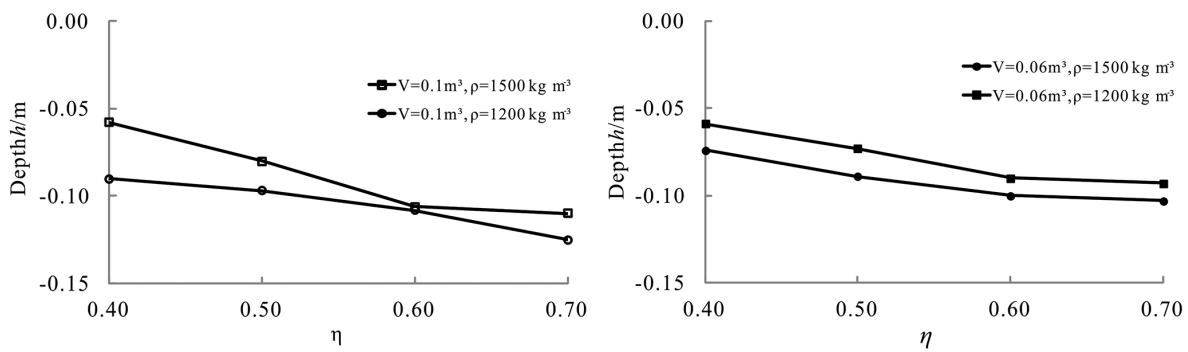

Figure 11. Comparison of scour depth at different debris-flow densities.

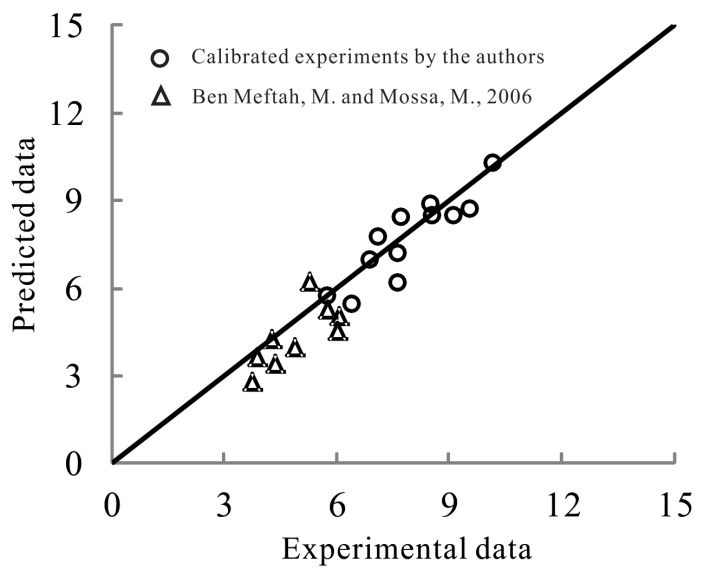

Figure 12. Comparison between predicted and experimental data.

1. Flow patterns were mainly determined by the lateral contraction ratio. At a high lateral contraction ratio, the spillway effectively extended the debris-flow nappe and increased the distance between the plunge point and the dam toe. The drop length of the nappe at $\eta=0.7$ was approximately 1.4 times higher than that at $\eta=0.4$.

2. The plunge pool downriver of a check dam inevitably dissipated the kinetic energy of the debris flow after overflowing the check dam. The collision and friction between the debris-flow nappe and the debris flow in the plunge pool dissipated the kinetic energy of the flow, ranging from 42.03 to $78.08 \%$ at different contraction ratios. Generally, increasing the contraction ratio increased the energy dissipation rate at the same debrisflow scale.

3. An empirical model was proposed to predict the maximum scour depth downriver of a check dam. The results indicated that the predicted results exhibited good agreement with the experimental results. The absolute error was smaller than $15.0 \%$ in most cases.

\subsection{Discussions}

The characteristics of debris flow nape and scour downriver of a check dam with different spillway were experimentally investigated in this article. Although the size of the model in our experiments is relatively small, the experimental results can still account for the interaction between the debris flows and erodible bed under certain hydraulic structure. When the experimental data are used to predict debris-flow motion and scour feature downriver of a check dam in prototype, the effects of physical model scale should be considered. The scaling effect is mainly induced by dissatisfaction of mobility similitude of model sediment in physical model experiments and it leads to discrepancies between the estimated and actual scour results. Just like the experimental investigation on the scale effect in pier-scour experiments, the bed-particle mobility similitude (Ettema et al., 1998; Ettema and Melville, 1999) or the flow-strength similitude (Lee and Sturm, 2009) should be satisfied to weaken or eliminate the scaling effect for debris-flow scour when the experimental results are extrapolated to predict prototype performance. Additionally, the experimental results obtained in large-scale models are undoubtedly closer to the prototype results than those in small-scale models.

When debris flows occur in the mountainous areas with forest the driftwood carried by debris flows is a common phenomenon. The debris flows combined with driftwood will speed up blockage and jamming of a check dam. Once the spillway is blocked by the driftwood the subsequent debris flows will overflow from the crest of a check dam, which will cause extensive scour downriver of a check dam. Therefore, it is also necessary to investigate the behavior of debris flows with driftwood and propose some reasonable structural or non-structural countermeasures to mitigate the effects of debris flows with driftwood on the operation of a check dam in the future. 


\section{Appendix A: List of symbols}

ai The index for the dimensionless parameter (-)

$b \quad$ The width of the spillway outlet (m)

$B \quad$ The width of the spillway inlet (m)

$d_{90} \quad$ The characteristic particle size for erodible bed materials $(\mathrm{m})$

$k \quad$ The coefficient for the dimensionless equation (-)

$h_{1} \quad$ The depth of debris flows at reference cross sections \#1 (m)

$h_{2} \quad$ The depth of debris flows at reference cross sections \#2 (m)

$h_{\mathrm{d}} \quad$ The maximum scour depth (m)

$h_{\mathrm{w}} \quad$ The water head loss (m)

$g \quad$ The acceleration of gravity $\left(\mathrm{m} \mathrm{s}^{-2}\right)$

$q \quad$ The unit discharge of the debris flow $\left(\mathrm{m}^{3} \mathrm{~s}^{-1}\right)$

$v \quad$ The initial velocity of the debris flow flowing out of the spillway $\left(\mathrm{m} \mathrm{s}^{-1}\right)$

$v_{1} \quad$ The velocity of debris flows at reference cross sections \#1 $\left(\mathrm{m} \mathrm{s}^{-1}\right)$

$v_{2}$ The velocity of debris flows at reference cross sections \#2 $\left(\mathrm{m} \mathrm{s}^{-1}\right)$

$V \quad$ The scale of debris flow in the experiments $\left(\mathrm{m}^{3}\right)$

$x \quad$ Trajectory in the horizontal direction $(\mathrm{m})$

$y \quad$ The water elevation difference $(\mathrm{m})$

$Z_{1} \quad$ The elevation of reference cross sections at \#1 (m)

$Z_{2} \quad$ The elevation of reference cross sections at \#2 (m)

$\Delta z \quad$ The elevation difference between the two reference cross sections (m)

Greek letters

$\alpha_{1} \quad$ The kinetic energy correction coefficient for $v_{1}(-)$

$\alpha_{2} \quad$ The kinetic energy correction coefficient for $v_{2}(-)$

$\rho_{\mathrm{d}} \quad$ The density of debris flows $\left(\mathrm{kg} \mathrm{m}^{-3}\right)$

$\rho_{\mathrm{w}} \quad$ The density of clear water $\left(\mathrm{kg} \mathrm{m}^{-3}\right)$

$\zeta \quad$ The energy dissipation coefficient (-)

$\eta \quad$ The lateral contraction ratio (-)

$\varphi \quad$ The angle of the initial velocity in the horizontal direction $\left(^{\circ}\right)$ 
Acknowledgements. The study results presented in this paper were supported by the Science Technology Service Network Initiative, Chinese Academy of Sciences (Grant No. KFJ-EWSTS-094), the National Natural Science Foundation of China (Grant No. 51209195; 41190084), the Key Research Program of the Chinese Academy of Sciences (Grant No. KZZD-EW-05-01), and the Key Laboratory of Mountain Hazards and Earth Surface Process, Chinese Academy of Sciences.

Edited by: P. Bartelt

Reviewed by: two anonymous referees

\section{References}

Abedini, M., Said, M. A. M., and Ahmad, F.: Effectiveness of check dam to control soil erosion in a tropical catchment (The Ulu Kinta Basin), Catena, 97, 63-70, 2012.

Adamkowski, A., Janicki, W., Kubiak, J., Kubiak, J., Urquiza, G., Sierra, F., and Fernández D., J. M.: Water turbine efficiency measurements using the gibson method based on special instrumentation installed inside pipe-lines/Proceedings of the 6th International Conference on Innovation in Hydraulic Effi-ciency Measurements, Portland, Oregon, USA, 30 July-1 August, 1-12, 2006.

Adduce, C., La Rocca, M., and Sciortino, G.: Local Scour Downstream of Grade Control Structures in Urban Stream Restoration, Enhancing Urban Environment by Environmental Upgrading and Restoration Nato Science Series IV, Earth Environ. Sci., 43, 307317, 2005.

Ben Meftah, M. and Mossa, M.: Scour holes downstream of bed sills in low-gradient channels, J. Hydraul. Res., 44, 497-509, 2006.

Bormann, E. and Julien, P. Y.: Scour Downstream of Grade-control Structures, J. Hydraul. Eng., 117, 579-594, 1991.

Chu, K. J., Hua, Z. L., and Ji, L. J.: Aeration at overflow dams with curved surfaces by different flashboard spillways, J. Environ. Eng. Landsc., 22, 226-236, 2014.

Cui, P., Zhou, G. D., Zhu, X. H., and Zhang, J. Q.: Scale amplification of natural debris flows caused by cascading landslide dam failures, Geomorphology, 182, 173-189, 2013.

Duarte, R., Schleiss, A. J., and Pinheiro, A.: Influence of jet aeration on pressures around a block embedded in a plunge pool bottom, Environ. Fluid Mech., 15, 673-693, 2015.

Ettema, R., Melville, B. W., and Barkdoll, B.: Closure of "Scale Effect in Pier-Scour Experiments", J. Hydraul. Eng.-ASCE, 124, 639-642, 1998.

Heumader, J.: Technical debris-flow coun-termeasures in Austria - a review, Proceedings, Second International Conference on Debris-Flow Hazards Mitigation: Mechanics, Prediction, and Assessment, Taipei, Taiwan, 16-18 August, 553-564, 2000.

Iverson, R. M.: The physics of debris flows, Rev. Geophys., 35, 245-296, 1997.
Lee, S. O. and Sturm, T. W.: Effect of Sediment Size Scaling on Physical Modeling of Bridge Pier Scour, J. Hydraul. Eng.-ASCE, 135, 793-802, 2009.

Lenzi, M. A.: Stream bed stabilization using boulder check dams that mimic step-pool morphology features in Northern Italy, Geomorphology, 45, 243-260, 2002.

Lien, H. P.: Design of Slit Dams for Controlling Stony Debris Flows, Int. J. Sediment Res., 18, 74-87, 2003.

Mizuyama, T.: Structural countermeasures for debris flow disasters, Int. J. Eros. Contr. Eng., 1, 38-43, 2008.

Ni, H. Y., Zheng, W. M., and Tie, Y. B.: Formation and characteristics of post-earthquake debris flow: a case study from Wenjia gully in Mianzhu, Sichuan, SW China, Nat. Hazards, 61, 317335, 2012.

Pagliara, S., Roy, D., and Palermo, M.: 3D plunge pool scour with protection measures, J. Hydro-Environ. Res., 4, 225-233, 2010.

Pan, H. L., Wang, R., Huang, J. C., and Ou, G. Q.: Study on the ultimate depth of scour pit downstream of debris flow check dam based on the energy method, Eng. Geol., 160, 103-109, 2013.

Remaître, A. and Malet, J. P.: The effectiveness of torrent check dams to control channel instability: example of debris-flow events in clay shales. Check dams, morphological adjustments and erosion control in torrential streams, Nova Science Publishers Inc., New York, 211-237, 2010.

Remaître, A., van Asch, Th. W. J., Malet, J.-P., and Maquaire, O.: Influence of check dams on debris-flow run-out intensity, Nat. Hazards Earth Syst. Sci., 8, 1403-1416, doi:10.5194/nhess-81403-2008, 2008.

Tang, C., Jiang, Z., and Li, W.: Seismic Landslide Evolution and Debris Flow Development: A Case Study in the Hongchun Catchment, Wenchuan Area of China, Eng. Geol. Soci. Terr., 2, 445-449, 2015.

Toombes, L., Wagner, C., and Chanson, H.: Flow patterns in nappe flow regime down low gradient stepped chutes, J. Hydraul Res., 46, 4-14, 2008.

Wang, G. L.: Lessons learned from protective measures associated with the 2010 Zhouqu debris flow disaster in China, Nat. Hazards, 3, 1835-1847, 2013.

Wang, Z. Y., Melching, C. S., Duan, X. H., and Yu, G. A.: Ecological and hydraulic studies of step-pool systems, J. Hydraul. Eng., 9, 705-717, 2009.

Wang, Z. Y., Qi, L. J., and Wang, X. Z.: A prototype experiment of debris flow control with energy dissipation structures, Nat. Hazards, 60, 971-989, 2012.

Yu, B., Ma, Y., and Wu, Y.: Case study of a giant debris flow in the Wenjia Gully, Sichuan Province, China, Nat. Hazards, 65, 835849, 2013.

Yu, G. A., Wang, Z. Y., and Duan, X. H.: Artificial step-pool system for ecological restoration of a debris-flow ravine, Proceedings of 32nd IAHR congress, 1-10 July 2007, Venice, Italy, 2007. 